\title{
Stomach Cancer: Surgical Management and Impact of Lymph Node Dissection in Survival at the Surgery " $A$ " Department of the National Hospital of Point "G" (Mali)
}

\author{
Sidiki Keita1 ${ }^{*}$, Koniba Keita ${ }^{2}$, Moussa Sissoko, Mahamadou Coulibaly', Lamine Soumare1, \\ Oumar Sacko', Sekou Koumaré ${ }^{1}$, Adama K. Koita ${ }^{1}$, Soumaîla Keita ${ }^{1}$, Zimogo Zié Sanogo ${ }^{1}$ \\ ${ }^{1}$ General Surgery “A” Department, Hospital Point-G., Bamako, Mali \\ ${ }^{2}$ General Surgery Department, Hospital BSS, Kati, Mali \\ Email: *sidikibafing@yahoo.fr
}

How to cite this paper: Keita, S., Keita, K., Sissoko, M., Coulibaly, M., Soumare, L., Sacko, O., Koumaré, S., Koita, A.K., Keita, S. and Sanogo, Z.Z. (2020) Stomach Cancer: Surgical Management and Impact of Lymph Node Dissection in Survival at the Surgery "A" Department of the National Hospital of Point "G" (Mali). Surgical Science, $11,458-468$.

https://doi.org/10.4236/ss.2020.1112048

Received: November 10, 2020

Accepted: December 21, 2020

Published: December 24, 2020

Copyright $\odot 2020$ by author(s) and Scientific Research Publishing Inc. This work is licensed under the Creative Commons Attribution International License (CC BY 4.0).

http://creativecommons.org/licenses/by/4.0/

\section{(c) (i) Open Access}

\begin{abstract}
Introduction: Although its incidence has tended to decrease for several years, stomach cancer remains one of the most frequently diagnosed cancers worldwide. Globally, gastric cancer is the $4^{\text {th }}$ most common cancer in men, the $5^{\text {th }}$ in women, and the third leading cause of cancer death in men, the $5^{\text {th }}$ in women. Patients and Methods: This was an analytical, prospective and descriptive study. Study Framework: Our study took place in the "A" surgery department of the Point "G" Hospital in Bamako. Study Period: August 1, 2003 to August 31, 2005. The design and preparation phase of the fact sheet lasted 1 month. The data collection phase lasted 18 months. All the patients who consulted for gastric tumor had a record. The follow-up phase of the patients lasted 6 months during which the patients were followed by appointment, by contact person or seen at home. Data entry and analysis were conducted with Epi-Info software (version 6.0). Inclusion Criteria: All patients hospitalized for gastric cancer in the " $A$ " surgery department of the Point " $G$ " Hospital. Result: The distribution of patients according to the evolutionary stage TNM was: Stage IV (50 cases, or 64.94\%); Stage III (21 cases, or $27.27 \%$ ); Stage II (6 cases, or 7.79\%). In our series the average age was 59 with extremes of 20 to 85 years. The most represented age group was 46 - 65 years. Men were 60 cases $(77.90 \%) 17$ cases for women $(22.10 \%)$. The sex ratio was 3.53 in favor of men. All 77 patients were recruited during the outpatient clinic, including 55 patients referred by a physician and 20 patients who came by themselves. Esogastroduodenal fibroscopy was performed in all of our patients. The tumor was localized: to the cardia in 10 cases; cardiac fundus in 2
\end{abstract}


cases; antrum in 24 cases; antro-pyloric in 28 cases; Pylorus in 1 case; great curvature in 5 cases; small curvature in 2 cases. Postoperative complications were: parietal infection in 12 cases or $17.40 \%$; digestive fistula in 3 cases and evisceration is $1.40 \%$. The overall three-month survival rate was $51.90 \%$ and at 6 months was $48.10 \%$. Conclusion: Stomach cancer is the most common digestive cancer in Mali. In Africa the diagnosis is usually late and the R1 lymph node dissections remain the basic technique, despite the results obtained in the Japanese series. The results of several major series argue for their effectiveness in improving patient survival.

\section{Keywords}

Cancer, Stomach, Resectability, Lymph Node Dissection, Survival

\section{Introduction}

Although its incidence has tended to decrease for several years, stomach cancer remains one of the most frequently diagnosed cancers worldwide. Globally, gastric cancer is the $4^{\text {th }}$ most common cancer in men, the $5^{\text {th }}$ in women, and the third leading cause of cancer death in men, the $5^{\text {th }}$ in women [1]. Its incidence is particularly high in Asia (nearly 100/100,000 inhabitants in Japan) [2]. In Europe, Portugal has the highest incidence (31.9/100,000 for men and 14.6/100,000 for women) [2]. In France, the decrease in the incidence of gastric cancers has possibly reached a threshold since the number of new cases was 6550 in 2012 and 6585 in 2015, half of the cases are diagnosed after 75 years [1]. In Switzerland, stomach cancer affects about 1100 people each year (16 out of 100,000) [3]. In Africa few studies have addressed this aspect of the issue while gastric cancer is the first cancer of the digestive tract [4] [5] [6] [7].

Lymph node dissection during cancer gastrectomies was systematically performed and studied by the Japanese [8] [9]. The results of several major series argue for their effectiveness in improving patient survival [10] [11] [12] [13]. However, to this date, no randomized studies have compared in terms of survival the traditional, limited dissections (called $\mathrm{R} 1$, where $\mathrm{R}$ is resectability or radicality) to extensive dissections (called R2 and R3). If the surgical technique of these extensive lymph node removals is well controlled by the Japanese as well as by the Germans because of their close surgical relationships for a long time, this is not the case in most other countries, where traditional R1-type dissections remain the basic technique [9] [14].

The procedures for collecting and studying the lymph nodes differ a great deal from team to team, especially since the final result (the lymph node status) depends on two different entities: the surgeon and the pathologist. Therefore, it is difficult to compare the results of different teams, and we can question the validity of multicenter studies evaluating therapeutics when based on lymph node status. The overall objective was to describe stomach cancer in its epidemiologi- 
cal, clinical, para-clinical and therapeutic aspects.

The specific objectives were to: determine the frequency of stomach cancer in relation to cancers of the digestive tract; describe the different clinical conditions and therapeutic management; research the influence of lymphadenectomy in stomach cancer on morbidity, mortality and 5-year survival from the literature.

\section{Patients and Methods}

Type of study: This was an analytical, prospective and descriptive study.

Study Framework: Our study took place in the "A" surgery department of the Point "G” Hospital in Bamako.

Study period: Our study ran from August 1, 2003 to August 31, 2005.

The design and preparation phase of the fact sheet lasted 1 month. The data collection phase lasted 18 months. All the patients who consulted for gastric tumor had a record. The follow-up phase of the patients lasted 6 months during which the patients were followed by appointment, by contact person or seen at home. All the patients in this study were subjected to a previously established informed consent questionnaire and gave their signed consent. Ethics clearance for this study has been granted.

Inclusion criteria: All patients hospitalized for gastric cancer in the " $\mathrm{A}$ " surgery department of the Point "G" Hospital.

Exclusion criteria: All patients hospitalized for gastric cancer whose file is incomplete.

The data were entered on Word 2018 software, analyzed by SPSS 21 French version and processed on Excel 2018 and Epi-info software with a significant difference if $\mathrm{P}$ is less than or equal to 0.05 .

\section{Results}

In our series the average age was 59 with extremes of 20 to 85 years. The most represented age group was 46 - 65 years. Men were 60 cases $(77.90 \%) 17$ cases for women (22.10\%). The sex ratio was 3.53 in favor of men. All 77 patients were recruited during the outpatient clinic, including 55 patients referred by a physician and 20 patients who came by themselves. The reason for consultation was epigastralgia in 37 patients, vomiting in 20 patients and epigastralgia-vomiting association was present in 13 patients. The consultation period was 1 to 6 months in 29 patients and 6 months to one year in 29 patients. 42 patients had resorted to traditional treatment. The track record was: gastric ulcer in 38 cases or $49.35 \%$, chronic gastritis in 7 cases or $9.09 \%$, gastrectomy stump for cancer in 1 case or $1.30 \%$, undetermined causes in 31 cases or $40.26 \%$ and 2 cases or $2.60 \%$ history of gastric cancer in the family. The physical signs found at the palpation of the abdominal were: abdominal tumor (19 cases); ascites (13 cases); tumoral liver ( 1 case); Troisier's ganglia (9 cases); rectal tumor (2 cases); dehydration folds (33 cases). Esogastroduodenal fibroscopy was performed in all of our patients. The tumor was localized: to the cardia in 10 cases; cardiac fundus in 2 
cases; antrum in 24 cases; antro-pyloric in 28 cases; Pylorus in 1 case; great curvature in 5 cases; small curvature in 2 cases. The tumor was budding in 52 cases; ulcerative in 15 cases; ulcero-budding in 10 cases. The histological types of the tumor were: adenocarcinoma (65 cases, or $84.4 \%$ ), squamous cell carcinoma (10 cases, or $13.0 \%$ ); lymphoma (2 cases, or $2.6 \%$ ). The location of metastases was: liver in 8 cases or $10.39 \%$; lymph nodes in all patients or $100 \%$; peritoneal in 13 cases or $16.88 \%$. The type of procedure was based on the site of the tumor. Of the 77 patients in our series, 8 patients were not operated on. The distribution of patients according to the evolutionary stage TNM was: Stage IV (50 cases, or $64.94 \%$ ); Stage III (21 cases, or 27.27\%); Stage II (6 cases, or 7.79\%). Postoperative complications were: parietal infection in 12 cases or $17.40 \%$; digestive fistula in 3 cases and evisceration is $1.40 \%$. The overall three-month survival rate was $51.90 \%$ and at 6 months was $48.10 \%$.

\section{Discussion}

The study period ran from August 1, 2016 to August 1, 2018. It was prospective and had involved 77 patients operated on in the surgery department " $A$ " of the Teaching Hospital of Point G in Bamako. Although its incidence has tended to decrease for several years, stomach cancer remains one of the most diagnosed cancers worldwide, with a particularly high incidence in Africa [5] [6] [7], in Asia nearly 100/100,000 inhabitants in Japan) [2]. In Europe it is in Portugal and Italy that its incidence is highest with $31.9 / 100,000$ respectively in men and $4 / 100,000$ in women [15] [16]; 31.3/100,000 in men and 14.4/100,000 in women [2]. The average age was 59. Sawadogo A et al. [5] and Traoré BK [7] found 56 years and 53 years respectively. In France as in Europe gastric cancer is rare before the age of 50 and the average age at the time of diagnosis is higher for women (71 years) than for men (67 years) [17] [18] [19] [20]. Men were the most affected than women (sex ratio 3.53). This male predominance was observed by African series 1.9 and 1.47 sex ratio respectively [5] [6]. In France as in Europe, the sex ratio is 2 to 3 men for a woman [2].

The majority of patients were referred by medical doctors (71.40\% of cases), 20 patients or $26 \%$ had come by themselves. Sacko O [21] had found 26/36 or $72.2 \%$ of patients referred by a doctor. $94.8 \%$ of our patients consulted at least 6 months after the onset of the disease. This delay could be explained by self-medication, traditional therapy and low socio-economic level that may prevent people from seeing a doctor. For Karayuba $\mathrm{R}$ et al. [22], the low socio-economic level of $69 \%$ of their patients could explain this delay.

Gastric ulcer (49.35\% of cases), chronic gastric (9.09\% of cases), history of gastric cancer in the family (2.60\% of cases), Helicobacter pylori infection were the most recorded history. The actual frequency of gastric cancer in patients followed for ulcerative disease is still controversial [23]. Most authors agree that the frequency of gastric cancer is higher in subjects who have or have had a gastric ulcer than in the general population, this frequency may reach a rate of $4 \%$ in 
some studies [23]. The prevalence of familial forms of gastric cancer, defined by at least 2 cancers in $1^{\text {st }}$ degree relatives, was about $12 \%$ and the relative family risk ranged from 2 to 3 [24]. The family risk is more important among siblings than between parents and children [24]. Helicobacter pylori infection was not sought due to the high cost of examining its outbreak in Mali. In addition, a recent meta-analysis of 5 cohort studies and 14 case-control studies (2491 patients, 3959 controls) showed a relative risk of gastric cancers (IC 95\%-1.32-2.78) in subjects infected with Helicobacter pylori. This increased risk of gastric cancer in subjects infected with Helicobacter pylori is found in intestinal forms and diffuse forms of gastric cancer, with the exception of cardiac topography cancers [13] [25]. Clinical signs were dominated by epigastralgia (48.1\%); post-prandial dietary vomiting (26\%); dysphagia (3.90\%). Epigastralgia is always associated with other signs such as vomiting and dysphagia. Vomiting is caused by delayed consultation. Physical signs were dominated by the presence of epigastric mass 24.68\% (19/77 cases); ascites 16.88\% (13/77); palpation of Troisier's Ganglia (11.9\%). In Japan and Germany patients are no longer seen at this stage thanks to routine screening campaigns [9] [26] [27]. The tumor was budding in $67.5 \%$ (52/77 cases); ulcerative-budding in 13\% (10/77 cases) and ulcerative in 19.5\% (15/77 cases).

The majority of stomach cancers were in the antro-pyloric distal portion (Table 1). Anatomopathologically adenocarcinoma was largely in the head with 65 cases or $84.4 \%$. In other series [8] [17] [28] this distribution was identical with rates of $92 \%$ respectively; $87.2 \%$ and $87.7 \% .71 .43 \%$ of our patients had liver metastases (10.39\% of cases); lymph nodes (86.96\%). These high rates can be explained by the delay in consultation with our patients. It must be recognized that the appreciation of lymph node invasion in our series was only subjective. It was based on the surgeon's own experience in being able to macroscopically identify an invaded lymph node so had no scientific basis. Out of 36 patients with upper-third adenocarcinoma of the stomach, the authors [10] had a node invasion jump directly from $\mathrm{N} 1$ to $\mathrm{N} 4$ in $17 \%$ of patients. This is why it is mandatory to have an anatomopathologist to perform extemporaneous examinations of the lymph nodes taken.

In our series as well as for the other authors [8] [28] [29] gastric cancers are seen in stage III or IV, this could be explained by the delay in consultation. In Japan, patients consult at the infra-clinical stage [9] [10] [11] [30] through mass

Table 1. Tumor topography according to the authors.

\begin{tabular}{lcccccccc}
\hline \multirow{2}{*}{ Authors } & \multicolumn{2}{c}{$\begin{array}{l}\text { Dominique A. et al. } \\
\text { [30] 1995 Calvados }\end{array}$} & $\begin{array}{c}\text { Sawadogo A. et al. [5] } \\
\text { 2000 Burkina Faso }\end{array}$ & $\begin{array}{c}\text { Traoré BK. [7] } \\
\text { 2000 Mali }\end{array}$ & Our series \\
\cline { 2 - 9 } & Size & $\%$ & Size & $\%$ & Size & $\%$ & Size & $\%$ \\
\hline \multicolumn{1}{c}{ Cardiac } & $132 / 970$ & & $4 / 94$ & & $12 / 160$ & 7.5 & 10 & 13.0 \\
Body and Fundus & $301 / 970$ & 31 & $11 / 94$ & & 5 & 3.1 & 14 & 18.2 \\
Antrum and Pylore & $352 / 970$ & 36 & $79 / 94$ & 84.04 & 132 & 82.5 & 53 & 68.9 \\
\hline
\end{tabular}


screening campaigns, motivated by high rates of gastric cancer in that country. In Mali, the assessment of the evolutionary stage of stomach cancer is only subjective. The stage $\mathrm{T}$ must be determined before the intervention by ultrasound and during the ultrasound procedure and the extemporaneous examination of the exeresis part. The search for peritoneal metastases is performed by in-depth examination of the peritoneum and extemporaneous cytological examination on the peritoneal wash fluid during the operation [12]. Only the search for liver metastases is carried out by ultrasound and scan of the abdomen before the procedure in Mali.

The high resectability rate of our series $(59.42 \%)$ is identical to other series [30] [31], but lower than that of Traoré BK (25.6\%) [7]. This relatively high rate could be explained by our department's tendency to remove any removable tumor if the general conditions of intervention are permitted. The lower polar gastrectomy is most performed in the different series this could be explained by the frequency of antropyloric locations. In two retrospective studies from 1975 to 1985 and from 1986 to 1995, Seulin P et al. [13] found a significant increase between the two periods in the rate of total gastrectomies from $17 \%$ to $42 \%$. This difference can be explained by the abandonment of upper polar gastrectomy for cancers of the middle third and upper third of the stomach. The most common type of anastomosis was Billroth II (Finsterer) for cancers of the lower $2 / 3$ of the stomach. This attitude is the same for the other authors [5] but different from that of Traoré BK [7] who made the Billroth I (Pean) for the same locations.

The early spread of stomach cancer is caused by invading the locoregional ganglia, with later onset of blood-borne metastases. Exeresis of lymphatic metastases significantly alters remote survival [10] [11] [30] [32]. The purpose of surgical treatment of stomach cancer should therefore include not only the exeresis of the primary tumor but also that of all lymph node relays likely to be invaded. This logic does not seem as obvious when we consider the data of the literature. The extent of lymph node dissection remains a controversial topic. On the one hand, there are difficulties in establishing a relative preoperative staging of the $\mathrm{T}$ and $\mathrm{N}$ parameters, necessary to plan the extent of gastric and lymphatic exeresis, and there is on the other hand a significant increase in mortality and morbidity rates proportional to the extent of lymph node dissection. The place of the $\mathrm{D} 2$ dissection (D for dissection) is controversial and that of the super expanded dissection D4 is not defined by lack of precise indications. The importance of the extent of lymph node dissection has been the subject of much controversy between proponents of type D1 dissection, limited to perigastric ganglia up to $3 \mathrm{~cm}$ from the primary tumor and the proponents of more extensive dissections, based on Japanese works [13]. Three recent studies comparing D1 dissection to D2 dissection report higher surgical mortality and show a significant difference in mortality and morbidity against D2 lymphadectomies [31] [32].

In the Dutch study [32] the last part of which appeared in 1999 concerning lymph node dissections in stomach cancer. This study, well known now, of high 
quality, compared the D1 dissections (proximal node relays N1) to the D2 dissections (distal lymph node relays) to the Japanese. Quality control was organized so that a Japanese surgeon participated as a teacher and supervisor of Dutch surgeons during the first four months of the study, which ensured homogeneity in the realization of the gestures. This study randomized patients in each of the two groups: 380 were included in the D1 group and 331 in the D2 group from August 1989 to July 1993. Previous publications had found a significantly higher rate of complications in the D2 group than in the D1 group: $43 \%$ versus $25 \%$ $(\mathrm{p}<0.001)$ [32]. Surgical mortality was also higher in the $\mathrm{D} 2$ group: $10 \%$ versus $4 \%$ $(\mathrm{p}=0.004)$. The length of stay was also longer with 16 days for the D2 group compared to 14 days for the $\mathrm{D} 1$ group $(\mathrm{p}<0.001$ ). The re-intervention rate was also significant with $8 \%$ for D1 versus $18 \%$ for D2 $(\mathrm{p}<0.001)$. Excess mortality and morbidity were mainly blamed on the completion of a left spleen-pancreatectomy for patients in group D2. 5-year survival was similar in both groups: $45 \%$ for D1 and 47\% for D2. The confidence interval of $95 \%$ of the difference was between $9.6 \%$ and $5.6 \%$. Therefore, there is no difference in survival in the two groups. Similarly, the risk of recidivism was not significantly different, although slightly higher in the D1 group ( $43 \% \mathrm{D} 1,37 \% \mathrm{D} 2, \mathrm{p}>0.22$ ). The authors concluded that extensive D2 dissection in gastric cancer was useless in Western patients. In particular, therefore, splenectomy should not be part of a standard dissection during a cancer gastrectomy including, as in this study, for the proximal locations of the T3 or T4 stages.

In the study of Seulin P et al. [13] on two retrospective series of stomach cancer, spread out each over a period of 11 and 10 years, 106 patients were operated on from 1975 to 1985 and 99 from 1986 to 1995 for a gastric adenocarcinoma located at the lower third of the stomach respectively in $56 \%$ and $61 \%$ of cases and not differentiated in $56 \%$ of cases. In the first period were performed only lymph node D1 dissections while in the second, 43 patients had an extensive "type D2" dissection without systematic splenic and pancreatic resection (D 1.5). The rate of curative resection was higher in the second period ( $85 \%$ vs. $75 \%$ ). This attitude was motivated by the results of several Japanese studies [5] that showed an improvement in survival after D2-type lymphadectomies compared to conventional lymphadectomies. Surgical mortality decreased with the most recent period, a rate of $1 \%$ against $2 \%$ for the first period. The same is true of morbidity, which has increased from $33 \%$ to $15 \%$ with a decrease in the rate of anastomotic fistula (11\% to $2 \%$ ).

In the AURC randomized series [31] covering the period 1980-1985 with 169 patients, surgical mortality was $2.4 \%$ and morbidity was $33 \%$. The randomized study of Bozzeti et al. [33] which included 924 patients between 1982 and 1993 had a mortality rate of $2 \%$ and a morbidity rate of $13 \%$. These studies confirm the significant improvement in the series of Seulin P. et al. [13]. For the period of $1980-1995$, mortality was $20 \%$ of patients in the D1 group, $5 \%$ and $10 \%$ in the D1 group but $40 \%$ of patients in the D1 group, 5 groups had had an associated 
splenectomy. The Overall five-year survival improved from $29 \%$ in the first period to $38 \%$ for the most recent period. This improvement was more marked for $\mathrm{N}+$ patients with a $15 \%$ increase in survival. In addition, the comparison of the survivals of N+ patients born in 1897-1995 who had a D1 dissection and those who had a type D1 dissection 5 (24\% vs. $29 \%$ ) shows no significant difference.

In Europe many studies corroborate these results [11] [13] [30] [31]. These results reveal large differences (Table 2) between Japanese and Western patients [9]. In the USA (as in Europe and Africa), stomach cancers have the worst prognosis than in Japan (Table 2). The main explanations for these differences are: a delay in diagnosis in the absence of a routine screening program; older patients and less general condition more aggressive cancers with lower rates of "intestinal forms" and higher rates of "diffuse forms"; less careful anatomopathological studies; inadequate gastric exeresis and too often insufficient lymph node dissections.

In our series the overall 6-month survival rate was $48.10 \%$. This rate is lower than The Dieng M. [34] and Traoré BK. [7] one with $20 \%$ and 29.6\% respectively.

\section{Conclusion}

Despite a decrease in incidence in most Western countries, stomach cancer remains the first cancer of the digestive tract in Mali. The history of chronic atrophic gastritis, and a lesser degree of gastric ulcer are the main precancerous conditions identified for gastric cancer, while helicobacter pylori infection is arguably one of the most important etiological factors. The late diagnosis is affirmed by per-endoscopic biopsies. Extension and operability assessments would be based on clinical examination, chest X-ray, abdominal ultrasound, CT scan and esogastroduodenal transit. The treatment of stomach cancer is eminently surgical and cancers considered resectable must be operated on. In our department the main criteria of non-resectability are: the impossibility of freeing the stomach from the posterior wall of the abdomen, the presence of peritoneal carcinosis, the advanced age of the patient. Resection for antro-pyloric cancer is a distal subtotal gastrectomy with omentectomy followed by gastrointestinal anastomosis. The resection performed in the case of cancer of the middle and the upper $1 / 3$ is a total gastrectomy with an oeso-jejunal anastomosis in " $Y$ " according to ROUX. Survival was better each time that resection was considered

Table 2. Incidence and survival of 5-year-old stomach cancer. Comparison of North American and Japanese results according to Dominique Elias [9].

\begin{tabular}{ccccc}
\hline & Incidence (\%) & \multicolumn{2}{c}{ Survival at 5 years old } \\
\hline Stage & Japan & USA & Japan & USA \\
\hline I & 46 & 17.1 & 90.7 & 50 \\
II & 11.8 & 16.9 & 71.9 & 30 \\
III & 21.8 & 35.5 & 49.3 & 15 \\
IV & 20.4 & 30.5 & 9.1 & 5 \\
\hline
\end{tabular}


curative. We have never performed lymph node dissection as advocated by the Japanese Research Society for Gastric cancer, although the extent of lymph node dissection on 5-year survival is demonstrated. But this type of dissection has caused many controversies between the proponents of a type D1 dissection and the proponents of more extensive dissection.

\section{Conflicts of Interest}

The authors declare no conflicts of interest regarding the publication of this paper.

\section{References}

[1] Zaanan, A., Bouché, O., Benhaim, L., Buecher, B., et al. (2018) Gastric Cancer: French Intergroup Clinical Practice Guidelines for Diagnostics, Treatments and Follow-Up (SNFGE, FFCD, GERCOR, UNICANCER, SFCD, SFED, SFRO). Digestive and Liver Disease, 50, 768-779. https://doi.org/10.1016/j.dld.2018.04.025

[2] Sophie, D. and Antoine, A. (2001) Les cancers de l'estomac. Bulletin du Cancer, 88, 1105-1118.

[3] Prévention.ch/cancerestomac.html. Le cancer de l'estomac: Causes. Symptomes. Diagnostic. Traitement. Pronostic.

[4] Koffi, E. and Kouassi, J.C. (1999) Le cancer gastrique aspects épidémiologiques et prise en charge en milieu tropical. Médicine d' Afrique Noire, 46, 52-55.

[5] Sawadogo, A., Ilboudou, P.D., Durant, G., Peghini, M., Branquet, D., Sawodogo, A.B. and Ouédraogo, I. (2000) Epidémiologie des cancers du tube digestif au Burkina Faso: Apport de 800 endoscopies effectuées au Centre Hospital National SanouSouro (CHNSS) de Bobo Dioulasso. Médecine d Afrique Noire, 47, 342-345.

[6] Mamoudou, G., Salamatou, H., Soulaymani, A., Quyou, A., Mahamadou, Z., Harouna, Nouhou, H. and Abdou, M. (2004) Les cancers du tube digestif. Revue de 195 dossiers. Médecine d Afrique Noire, 51, 585-588.

[7] Traoré, B.K. (2000) Cancer de l'estomac en chirurgie "B" de l'Hôpital du Point "G" de 1990 à 1997 à propos de 162 cas. Thèse de Méd., Bamako.

[8] Sirgon, R., Canzoniri, V., Cannizao, R. and Pasquoti, B. (1998) Early Gastric Cancer: Diagnostic Surgical. Treatment and Follow-Up of 45 Cases. Tumori, 84, 547-551. https://doi.org/10.1177/030089169808400507

[9] Dominique, E. (1995) Technique chirurgicale des curages ganglionnaires étendus (de type R2 et R3) pour adénocarcinomes gastriques. Annales de Chirurgie, 49, 13-23.

[10] De Manzoni, G., Di Leo, A., Borzellino, G., Pedrzzani, C., Tasseli, S., Castelli, A., Zerman, G. and Fersini, A. (2001) Envahissement des ganglions para-aortiques dans les adénocarcinomes de l'estomac. Annales de Chirurgie, 126, 302-307. https://doi.org/10.1016/S0003-3944(01)00521-1

[11] Marescaux, J. and Evrard, S. (1997) Curages ganglionnaires dans le cancer de l'estomac: Enjeux et techniques chirurgicales. In: Encyclopédie médico-chirurgicale, Elsevier, Paris, Techniques chirurgicales-Appareil digestif, 40-329, 5 p.

[12] Michel, D., Valérie, B., Julien, T., Emmanuel, M. and Philippe, R. (2000) La linite: Une forme particulière de cancer gastrique. Hépato-Gastro, 7, 263-267.

[13] Seulin, P., Carrière, N., Bloon, E., Pradère, B., Tap, G. and Gouzi, J.L. (2000) Cancer de l'estomac: Les changements dans la stratégie chirurgicale ont-ils une influence 
sur les résultats? Etude rétrospective sur 20 ans. Annales de Chirurgie, 125, 131-136. https://doi.org/10.1016/S0001-4001(00)00118-5

[14] Siewert, J.R., BÖttcher, K., Stein, H. and Roder, J.D. (1998) Relevant Pronostic Factors in Gastric Cancer. Ten-Year Results of the German Gastric Cancer. Annals of Surgery, 228, 449-461. https://doi.org/10.1097/00000658-199810000-00002

[15] Songun, I., Bonenkamp, J.J., Hermans, J., Van, Krieken, J.H.J.M. and Van de Velde, C.J.H. (1996) Pronostic Value of Resection-Line Involvement in Patients Undergoing Curative Resections for Gastric Cancer. European Journal of Cancer, 32, 433-437. https://doi.org/10.1016/0959-8049(95)00591-9

[16] Epidémiologie et facteurs de risque du cancer de l'estomac. http://www.zoomcancer.com/content/print/1.ONCGVQFRAFRAOPF3002ONC101 1

[17] Quinton, A. and Lamouliatte, H. (1983) Séquelles et complications tardives de la chirurgie gastrique. Encycl. Méd. Chir., Paris, Estomac-Intestin, 9029 B-10, 11-1983.

[18] Catherine, H. and Françoise, D. (2005) La fréquence des cancers en France en 2000 et son évolution depuis 1950. Bulletin du Cancer, 92, 7-11.

[19] Jean, F., Pascale, G., Guy, L., Patrick, A., Nicole, R., François, M., Patrice, P., Paul, S., Jean-Pierre, D. and Florent, V. (1997) Les cancers digestifs en France: Distribution géographique et estimation de l'incidence nationale. Gastroentérologie Clinique et Biologique, 21, 174-180.

[20] Maryvonne, P., Jean-Michel, C., Gérard, D., Jean-Baptiste, N., Lucile, E., Alain, G., Michel, R. and Hervé, G. (1995) Prise en charge thérapeutique et survie de l'adénocarcinome gastrique dans le département du Finistère entre 1984 et 1989. Gastroentérologie Clinique et Biologique, 19, 804-810.

[21] Sacko, O. (2001) Cancers de l'estomac en chirurgie "B" de l'hôpital du Point "G" de 1999-2001. Etude prospective (à propos de 39 cas). Thèse de Méd., Bamako-N 233.

[22] Karayuba, R., Armstrong, O., Bigirimana, V. and Durugserire, F.N. (1993) Le traitement chirurgical des cancers gastriques au CHU de Kamenge (Bujumbura) à propos de 53 cas. Médecine d' Afrique Noire, 40, 606-608.

[23] Mombet, J., Potet, F. and Vilotte, J. (1983) Cancer de l'estomac: Etats prédisposant au cancer et lésions précancéreuses de l'estomac. Définition d'une population à haut risque de cancer gastrique. Encycl. Méd. Chir. Estomac-Intestin; 1ère 2d., 6-1983-C. Tome 2, 9027. A10.

[24] Jean, F.B., Stéphane, C., Laurence, G. and Mael, P. (2003) Les cancers gastriques familiaux. Hépato-Gastro, 10, 247-255.

[25] Mégraud, F. (2001) Helicobacter pylori et cancer de l'estomac en 2001. http://www.snfge.asso.fr/01-bibliothèque/ob-conférences-flash/programmes/lundi 2001.asp

[26] Bonenkamp, J.J., Hermans, J., Sasako, M. and Van de Velde, C.J. (1999) Extended Lymph-Node Dissection for Gastric Cancer. Dutch Gastric Cancer Group Trial. New England Journal of Medicine, 340, 908-914. https://doi.org/10.1056/NEJM199903253401202

[27] Hautefeuille, P., Valleur, P., Castaing, D., Piel, J.L., Gerum, A., Houdard, R., et al. (1982) Influence de l'extension ganglionnaire sur la survie après la résection de cancers gastriques infiltrants. Gastroentérologie Clinique et Biologique, 9, 231-234.

[28] Parneix, M. (1983) Traitement chirurgical des complications tardives et séquelles de la chirurgie gastrique. Encycl Méd. Chir. (Elsevier, Paris), Estomac-Intestin, 9029 B-10, 11-1983. 
[29] Marc, Y., Pierre, S. and François, Q. (2000) Actualités en gastroentérologie. Bulletin Cancer, 87, 455-461.

[30] Dominique, A., Jaroslaw, C., Didier, P., Annie, R., Guy, L. and Marc, G. (1995) Epidémiologie et pronostic des carcinomes gastriques dans le département du Calvados. Etude sur 10 ans. Gastroentérologie Clinique et Biologique, 19, 797-803.

[31] Rignault, D. (1971) Séquelles générales et métaboliques de la chirurgie gastrique. EncyclmédChir (Elssevier, Paris), Techniques chirurgicales-Appareil digestif, 9029 D-10, 5-1971.

[32] Barrier, A., Huguier, M., Levard, H. and Montariol, T. (1999) Tumeurs gastriques conjonctives. Résultat d'une etude multicentrique. Chirurgie (Paris), 124, 494-502.

[33] Bozzeti, F., Marubini, E., Bonfanti, G., Miceli, R., Piano, C., Crose, N., et al. (1997) Total versus Subtotal Gastrectomy, Surgical Morbidity and Mortality Rates. Annals of Surgery, 226, 613-620. https://doi.org/10.1097/00000658-199711000-00006

[34] Dieng, M. (1998) Prise en charge des tumeurs gastriques à la clinique chirurgicale du CHU Aristide Le Dantec: Étude préliminaire (à propos de 60 cas). Thèse Méd., $\mathrm{N}^{\circ} 61$. 